\title{
Nonlinear Robust Backstepping Control for Three-Phase Grid-Connected PV Systems
}

\author{
Mohamed Habib Boujmil, ${ }^{1}$ Afef Badis $\mathbb{D}^{2},{ }^{2}$ and Mohamed Nejib Mansouri ${ }^{2}$ \\ ${ }^{1}$ Higher Institute of the Technological Studies of Nabeul, Nabeul, Tunisia \\ ${ }^{2}$ Electronics and Microelectronics Laboratory (E $\mu$ E), The National Engineering School of Monastir (ENIM), \\ University of Monastir, Monastir, Tunisia
}

Correspondence should be addressed to Afef Badis; badis.afef@gmail.com

Received 30 January 2018; Revised 3 May 2018; Accepted 30 May 2018; Published 25 June 2018

Academic Editor: Viktor Avrutin

Copyright (C) 2018 Mohamed Habib Boujmil et al. This is an open access article distributed under the Creative Commons Attribution License, which permits unrestricted use, distribution, and reproduction in any medium, provided the original work is properly cited.

\begin{abstract}
This paper proposes a cascade control structure for three-phase grid-connected Photovoltaic (PV) systems. The PV system consists of a PV Generator, DC/DC converter, a DC link, a DC/AC fully controlled inverter, and the main grid. For the control process, a new control strategy using nonlinear Backstepping technique is developed. This strategy comprises three targets, namely, DC/DC converter control; tight control of the DC link voltage; and delivering the desired output power to the active grid with unity power factor (PF). Moreover, the control process relies mainly on the formulation of stability based on Lyapunov functions. Maximizing the energy reproduced from a solar power generation system is investigated as well by using the Perturb and Observe (P\&O) algorithm. The Energetic Macroscopic Representation (EMR) and its reverse Maximum Control Structure (MCS) are used to provide, respectively, an instantaneous average model and a cascade control structure. The robust proposed control strategy adapts well to the cascade control technique. Simulations have been conducted using Matlab/Simulink software in order to illustrate the validity and robustness of the proposed technique under different operating conditions, namely, abrupt changing weather condition, sudden parametric variations, and voltage dips, and when facing measurement uncertainties. The problem of controlling the gridconnected PV system is addressed and dealt by using the nonlinear Backstepping control.
\end{abstract}

\section{Introduction}

Solar Photovoltaic (PV) energy is a potential and environmentally friendly resource of energy which has become widely explored till date owing to its omnipresence, availability, free gas emission, and reduced maintenance cost. In fact, gases emitted from the combustion of conventional fuel have dramatic drawbacks on living organs, human health, and the Ozone layer $[1,2]$.

Moreover, the PV output power is always changing with fast-changing weather conditions, e.g., solar irradiance level and temperature. Thus, adopting a Maximum Power Point Tracking (MPPT) technique is imperative as there is a probable mismatch between the Maximum Power Points (MPP) of the PV module and the load characteristics. Thanks to the MPPT, the effectiveness of the energy extraction is definitely improved [3], i.e., the total number of required PV panels is decreased, which reduces the total cost [4]. Perturb and
Observe (P\&O) method is the most widely used algorithm; it portrays a simplicity of use and easy implementation $[5,6]$.

Therefore, static converters (SCV) must be designed and controlled efficaciously to maximize the overall efficiency of the PV system in medium-voltage (MV) and low-voltage (LV). Usually, the solar energy is exploited either for standalone systems or for grid-connected Photovoltaic (PV) systems. Several papers in the literature are targeting the issue of grid-connected PV Generator (PVG) [7, 8]. Different converter structures have been proposed and/or studied in order to interface renewable energy systems in both gridconnected and stand-alone application $[9,10]$. In general, the boosting and the inverting stages in a grid-connected PV system present the two stages of the power conversion system for optimum power transfer. Because of the nonlinearity of the PV power systems and the unpredictable intrinsic and atmospheric changes, the operating point is always varying due to the control unit (DC/DC converter and/or inverter) 
and the parametric errors. Thus, the use of robust control laws becomes a required and challenging task for ensuring the stabilization and the good tracking. In fact, there are already a lot of researches [11-15] targeting the conversion chain of grid-connected PV system. However, the proposed schemes in the latter studies require the detailed evaluations, namely,

(i) control the DC/DC converter in order to force the PV array to operate at the Maximum Power Points (MPP);

(ii) maintain the DC link voltage at the desired constant value;

(iii) deliver the desired output power to the active grid with unity power factor (PF).

A considerable progress has been made over last decade in optimization techniques in order to perform the threefold objectives. Among these methods, classical PID controller is usually used in industry and literature because of its robustness, low cost, and ease of implementation. The conventional control strategies (PI regulator or state regulator) produce good results in linear systems [16]. However, for nonlinear systems or with varying parameters, those methods become insufficient and unreliable, especially, when the performance requirements of the system are rigorous. Thus, it is imperative to choose the adequate control strategy which is insensitive to parameter variations, perturbations, and nonlinearity. This paper proposes a Backstepping based technique to design a suitable control system for the grid-connected PV system. The designed control technique ensures the optimal energy transfer to the grid via sharing active and reactive power into the grid regardless of the atmospheric changes and parametric uncertainties. The desired DC link voltage is maintained as well by using Backstepping approach to control the static boost converter based on Matrix Topology (MT). MT is known to be the most industrially encountered in most power electronics systems since it does not need energy storage components. Control Lyapunov functions are formulated at different stages of the design process to evaluate the stability of the designed controller.

The PV system's operation and the development of its appropriate control techniques require, as a compulsory, a basic representation of the entire system by taking into consideration the integrality and the causality between every one of system's components.

The Energetic Macroscopic Representation (EMR) is a graphical portrayal of the system, which has been created in 2000 by the L2EP at the University of Lille in France. It is an extremely basic representation with a gathering of standards and elements $[17,18]$. Since then, EMR has been used as a part of many multidomain multisources $[19,20]$, for representation and modeling of different systems, namely, PV and wind energy conversion systems, Electric Vehicles (EV) [21].

In this paper, EMR and its reverse Maximum Control Structure (MCS) are both used to provide an instantaneous average model and a control structure based on cascade loops. The chosen structure gives promising dynamic performances and limits each state variable to manage the system in complete safety.

In the present study, the modeling of the Low-voltage grid-connected PV system is developed in Section 2. Section 3 encompasses the design of the proposed controller based on cascade Backstepping strategy. In Section 4, simulation results of the proposed control system are discussed for various operating conditions. Comments supporting the performance and robustness of the Backstepping control approach are given. Finally, in Section 5, the conclusion is drawn and followed by references.

\section{Modeling of the Grid-Connected Photovoltaic System}

The following section presents the equations used for modeling each component in the PV conversion chain. The principle mission of the chosen conversion system is to extract the maximum active power through a boost converter operating with a suitable MPPT and managing, as well, the active and reactive power injected into the grid via the inverter. The system is comprised of simple subsystems (pictograms) related together. These pictograms portray every element in the system by functions as shown in Table 1 [20]. The EMR for all components are interconnected in order to frame the entire system EMR, with respecting the integral causality and following the action-reaction principle. MCS which allows the control loop modeling is deduced by inversion of the EMR [20]. The entire grid-connected PV system is shows in Figure 1 while the EMR of the entire system is depicted in Figure 2.

The current electrical source (green oval) represents the PVG which is the association of series and/or parallel PV cells in order to raise the current, voltage, and power. An ideal Photovoltaic cell is equivalent to a power source shunted by a diode as shown in Figure 3 [22].

The PV model is mathematically modeled using

$$
I_{p v}=I_{p h}-I_{s}\left[\exp \left(\frac{U_{p v}}{N_{s} \cdot n \cdot K_{B} \cdot T}\right)-1\right]
$$

where

$$
\begin{aligned}
& I_{p h}=N_{p} \times i_{p h} \text { is photocurrent } \mathrm{N}_{\mathrm{p}} \text { parallel cells, } \\
& I_{p v}=N_{p} \times i_{p v} \text { is current supplied by } \mathrm{N}_{\mathrm{p}} \text { parallel cells, } \\
& I_{s}=N_{p} \times i_{s} \text { is reverse saturation current of } \\
& \mathrm{N}_{\mathrm{p}} \text { diode in parallel, } \\
& v_{T}=n K_{B} T / q \text { is the thermodynamic potential, } \\
& N_{p} \text { is number of cells in parallel, } \\
& N_{s} \text { is number of cells in series, } \\
& q \text { is electron charge }\left(1,6.10^{-19} \mathrm{C}\right), \\
& K_{B} \text { is Boltzman Constant }\left(1,38.10^{-23} \mathrm{j} / \mathrm{K}\right), \\
& T \text { is junction temperature } \mathrm{K}, \\
& \mathrm{n} \text { is ideality factor of the picture of the solar cell, } \\
& \text { including between } 1 \text { and } 5 \text { in practice. }
\end{aligned}
$$


TABLE 1: Elements of EMR and of control.

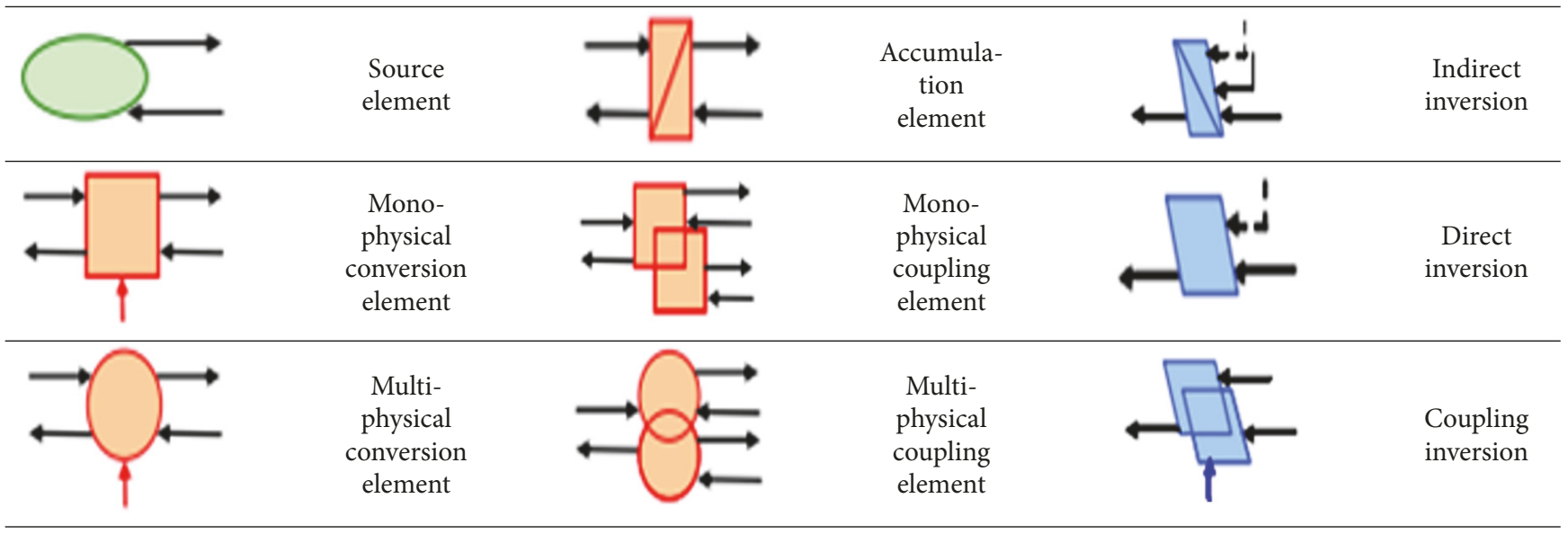

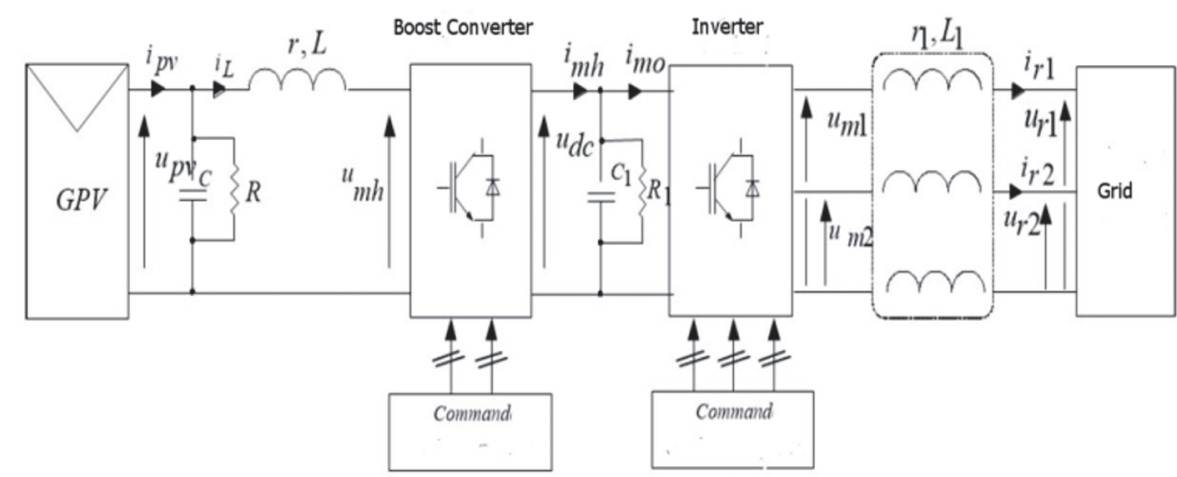

FIGURE 1: The grid-connected PV system chain.

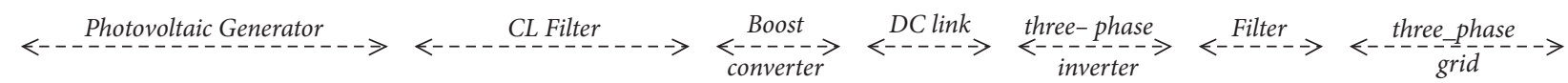

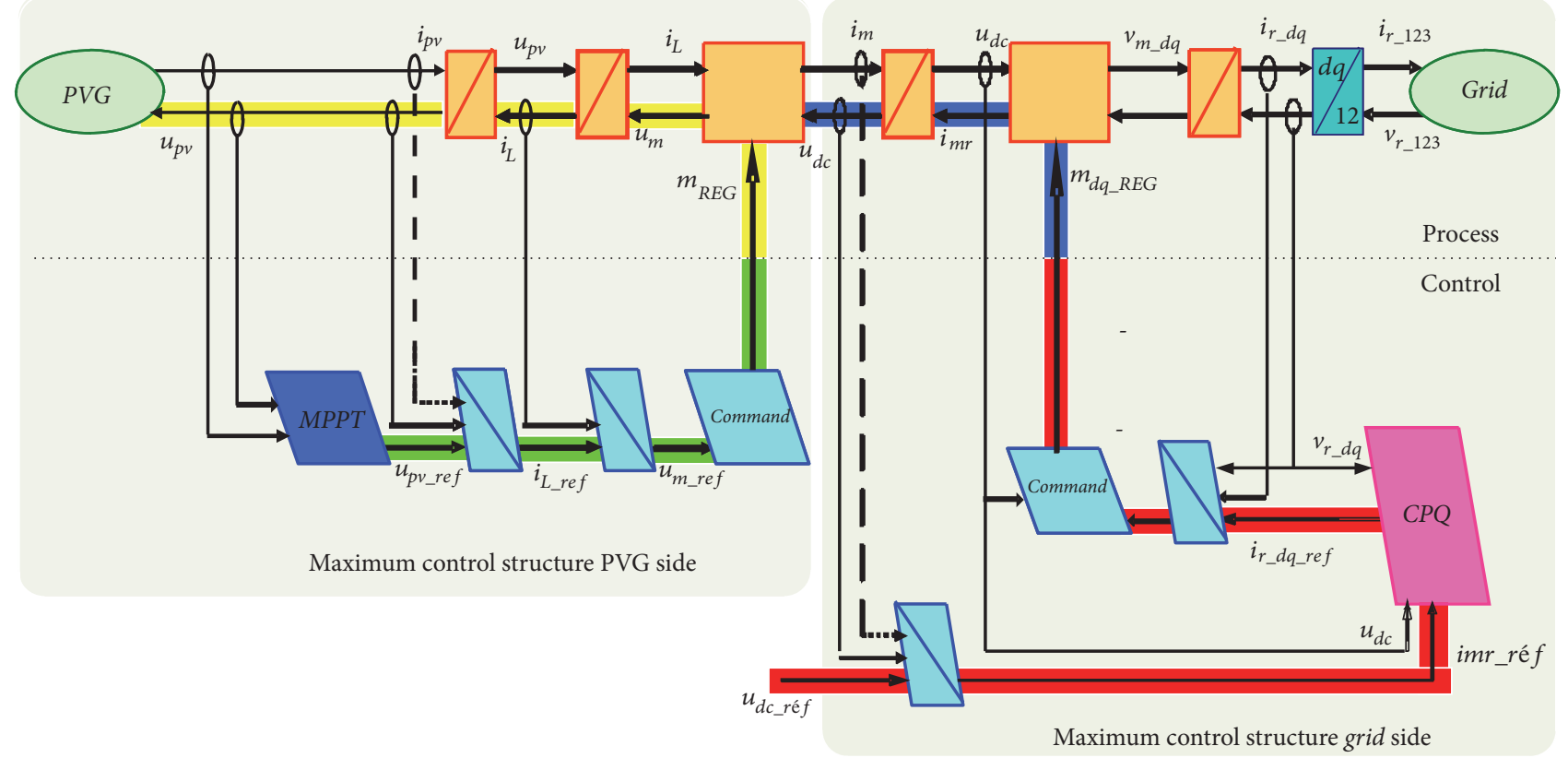

FIgURE 2: The EMR and its reverse MCS of the overall system. 


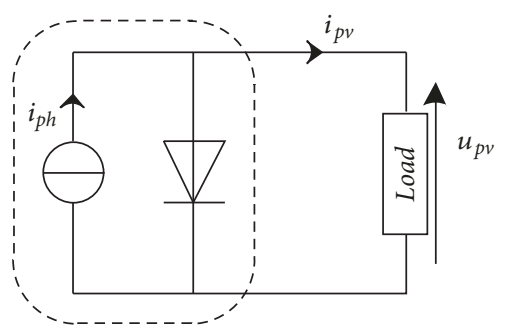

FIgURE 3: Equivalent circuit model of a solar PV cell.

The PVG pictogram delivers a current $\mathrm{i}_{\mathrm{PV}}$ and receives by reaction with the system the DC bus voltage $u_{p v}$ of the LC filter. The inductor and capacitor filters store energy. They are represented by two accumulation elements whose state variables are the current $i_{L}$ for the inductor and the voltage $u_{p v}$ for the capacitor. DC/DC and DC/AC converters (based on MT without energy storage) are represented by square pictograms. Both converters are modeled in average value (the switching functions are replaced by duty cycles) [21].

A capacitor $C$ is used for controlling the PV output voltage. It is modeled by means of the following equation:

$$
R_{1} \rightarrow C \frac{d u_{p v}}{d t}+\frac{u_{p v}}{R}=i_{p v}-i_{L}
$$

An inductor $\mathrm{L}$ is used to apply the source alternating rule. It can be modeled by the following differential equation:

$$
R_{2} \rightarrow L \frac{d i_{L}}{d t}+r . i_{L}=u_{p v}-u_{m h}
$$

The aim of the following subsection consists in modeling of the $\mathrm{DC} / \mathrm{DC}$ boost converter with matrix based topology. In fact, the DC/DC matrix based converter is a static devise which is initially proposed by Gyugi [23] in 1976. Since then, most of the published researches have dealt with threephase circuit topologies [24-26]. The basic problem to be addressed is to control the unregulated DC input voltage of the converter in order to reach the desired output voltage. The input of the boost converter consists of the PVG and the CL filter. This input is equivalent to a current source. While the boost output is connected to the DC link voltage which is equivalent to a voltage source. The matrix based boost structure is depicted in Figure 4.

The connection matrix is developed by

$$
[F]=\left[\begin{array}{ll}
f_{11} & f_{12} \\
f_{21} & f_{22}
\end{array}\right]
$$

and the conversion matrix is expressed by

$$
[M]=\left[\left(f_{11}-f_{12}\right)\right]
$$

In such a case, according to [27], the conversion matrix is reduced to a scalar representing the unique conversion function $m$. So, the modulated voltage $u_{m h}$ and current $i_{m h}$ are shown below:

$$
\begin{aligned}
& R_{m 1} \longrightarrow u_{m}=m_{h} \times u_{d c} \\
& R_{m 2} \longrightarrow i_{m}=m_{h} \times i_{L}
\end{aligned}
$$

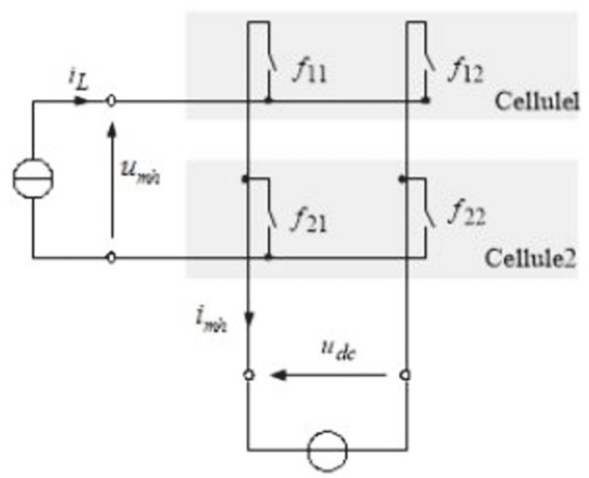

FIGURE 4: Operative system of the matrix based boost converter.

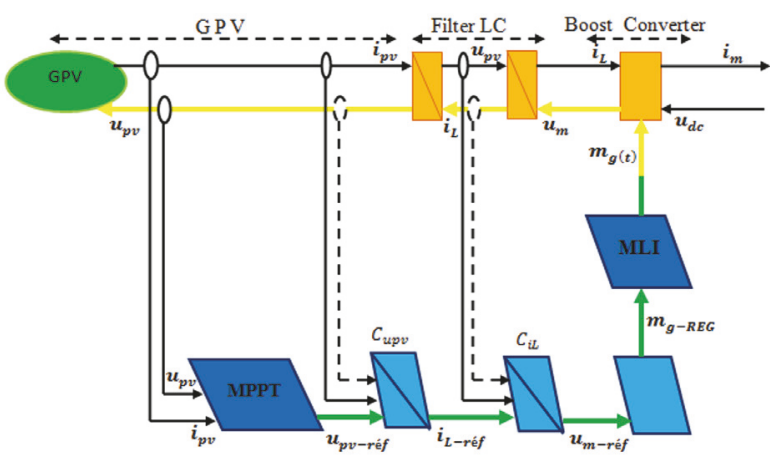

Figure 5: The EMR and its reverse MCS of the PVG side.

$m_{g}$ is the command variable of the boost converter. The EMR of the PVG side is illustrated in Figure 5.

For the grid side modeling, a capacitor $C_{1}$ is connected to the DC link for the purpose of controlling the voltage applied to the input of the three-phase inverter and maintaining it equal to a preset value. The voltage across $C_{1}$ can be described by the following differential equation:

$$
R_{3} \longrightarrow C_{1} \frac{d u_{d c}}{d t}+\frac{u_{d c}}{R}=i_{m}-i_{m r}
$$

The input can be considered as a voltage source. At the inverter output, an inductive filter is used to connect the inverter to the three-phase active grid. The grid and the filter all together are equivalent to a three-phase current source. A three-phase matrix converter topology shown in Figure 6 is used.

Instead of using the abc-frame, the Park transformation $P(\Theta)$ is used in order to transform currents and voltages to their equivalent components in the dq reference frame to get constant values which are easy to track.

The dynamic model is transformed from abc-frame to $d q$ reference frame and can be expressed by relations (7) to (15) of the grid side, and we take the angular frequency $\omega=2 \pi f$

The connection matrix of the inverter is developed by

$$
[F]=\left[\begin{array}{lll}
f_{11} & f_{12} & f_{13} \\
f_{21} & f_{22} & f_{23}
\end{array}\right]
$$




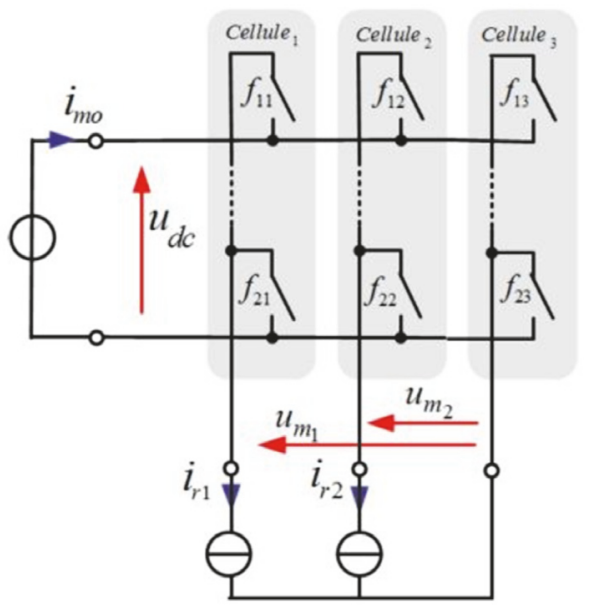

FIGURE 6: Operative system of the matrix based tree-phase inverter.

and the conversion matrix $[\mathrm{M}]$ is expressed by

$$
[M]=\left[\begin{array}{ll}
\left(f_{11}-f_{13}\right) & \left(f_{12}-f_{13}\right)
\end{array}\right]=\left[\begin{array}{ll}
m_{1} & m_{2}
\end{array}\right]
$$

The simple voltages and currents modulated by the inverter in the park reference can be expressed by

$$
\begin{gathered}
R_{m 3} \longrightarrow\left[\begin{array}{l}
v_{m d} \\
v_{m q}
\end{array}\right]=\frac{u_{d c}}{2}\left[\begin{array}{l}
m_{d} \\
m_{q}
\end{array}\right] \\
R_{m 4} \longrightarrow i_{m o}=\frac{1}{2}\left(m_{d} i_{r d}+m_{q} i_{r q}\right) \\
R_{4} \longrightarrow\left[\begin{array}{l}
v_{m d} \\
v_{m q}
\end{array}\right]=[P(\theta)]\left[\begin{array}{l}
v_{r 1} \\
v_{r 2}
\end{array}\right] \\
R_{5} \longrightarrow\left[\begin{array}{l}
i_{r d} \\
i_{r q}
\end{array}\right]=[P(\theta)]\left[\begin{array}{l}
i_{r 1} \\
i_{r 2}
\end{array}\right]
\end{gathered}
$$

where

$$
\begin{aligned}
{[P(\theta)] } & =\sqrt{\frac{2}{3}}\left[\begin{array}{cc}
\cos (\theta) & \cos \left(\theta-\frac{2 \pi}{3}\right) \\
-\sin (\theta) & -\sin \left(\theta-\frac{2 \pi}{3}\right)
\end{array}\right] \\
R_{6} & \longrightarrow\left(L_{1} \frac{d}{d t}+r_{1}\right)\left[\begin{array}{l}
i_{r d} \\
i_{r q}
\end{array}\right] \\
& =\left[\begin{array}{l}
v_{m d} \\
v_{m q}
\end{array}\right]-\left[\begin{array}{l}
v_{r d} \\
v_{r q}
\end{array}\right]+\left[\begin{array}{cc}
0 & L_{1} \omega \\
-L_{1} \omega & 0
\end{array}\right]\left[\begin{array}{l}
i_{r d} \\
i_{r q}
\end{array}\right]
\end{aligned}
$$

$\mathrm{P}$ and $\mathrm{Q}$ active and reactive powers, respectively, are computed using the conventional instantaneous power definition in $d q$ system [8] as shown in

$$
R_{7} \longrightarrow\left[\begin{array}{l}
P \\
Q
\end{array}\right]=\left[\begin{array}{cc}
v_{m d} & v_{m q} \\
v_{m q} & -v_{m d}
\end{array}\right]\left[\begin{array}{c}
i_{r d} \\
i_{r q}
\end{array}\right]
$$

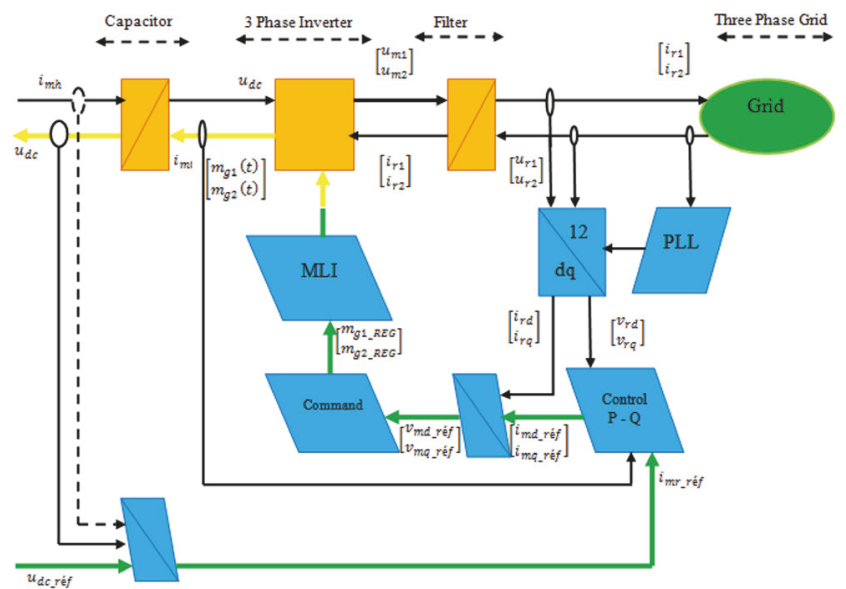

FIGURE 7: The EMR and its reverse MCS of the grid side.

The representation of DC link is an accumulation element. The grid with the filter are represented by source element and accumulation element, respectively, as portrayed in Figure 7.

where

(i) $r_{1}, L_{1}$ are the grid filter,

(ii) $i_{r d}$ and $i_{r q}$ are the $d q$ components of the line current,

(iii) $v_{r d}$ and $v_{r q}$ are the $d q$ components of the grid voltages,

(iv) $v_{m d}$ and $v_{m q}$ are the modulated voltages generated at the front end of the converter and considered as control laws,

(v) $\omega$ is the angular velocity of the grid voltages.

Based on the mathematical models of the PVG side in (1)-(6) and the grid side as described by (7)-(15), the nonlinear robust Backstepping control process is elaborately discussed in the next section.

\section{Backstepping Based Control of the Three-Phase Grid-Connected PVG}

The fundamental idea of Backstepping consists in conceiving (for each subsystem) a virtual control law. A Lyapunov function, which ensures the stability, is developed in order to exploit it later as a reference for the immediately superposed subsystem until the accurate command system directly involved in the static converter is obtained. Matrix converters are used instead of conventional converters using energy storage components.

3.1. Backstepping Based Cascade Control Sizing of the PVG Side. One of the main targets of this work is to make the PVG operate at its operating point MPPT. To do so, it is necessary to refer to the MCS of the PVG side [28]. The voltage $u_{p v}$ is chosen as an output and the control chain consists of two cascade controllers. As well, it is noticed that the controller $C_{u}$ not only insures the control of the voltage $u_{p v}$, but also provides the current reference $i_{\text {Lref }}$ (a virtual command) for 
the controller $C_{i}$ which insures the control of the inductance current $i_{L}$ and provides the real command $m_{g}$ of the boost converter. The relations associated with the EMR, on the PVG side, can be redefined as follows:

$$
\begin{aligned}
& \left(S_{1}\right) \Longrightarrow \frac{d u_{p v}}{d t}=\dot{u}_{p v}=-\frac{1}{R C} u_{p v}+\frac{1}{C} i_{p v}-\frac{1}{C} i_{L} \\
& \left(S_{2}\right) \Longrightarrow \frac{d i_{L}}{d t}=\dot{i}_{L}=-\frac{r}{L} i_{L}+\frac{1}{L} u_{p v}-\frac{1}{L} u_{m}
\end{aligned}
$$

while $u_{p v}$ and $i_{L}$ are the state variables and $m_{h}$ is the command variable of the boost converter. As the subsystem is a secondorder system, the design is performed in two stages.

Stage 1 (voltage loop across the PVG). The subsystem (S1) described via the relation (16) is considered, where the voltage $u_{p v}$ is taken as an output and the state variable $i_{L}$ is treated as a virtual control variable. This first stage is dedicated to identify the tracking error $e_{1}$, which corresponds the difference between the output PV voltage $u_{p v}$ and its reference $\mathrm{u}_{\mathrm{pv} \_ \text {ref. }}$ obtained from the MPPT bloc.

$$
e_{1}=u_{p v}-u_{p v_{-} r e f}
$$

According to relations (16) and (17), the dynamic equation of the error is deduced:

$$
\dot{e}_{1}=\dot{u}_{p v}-\dot{u}_{p v r r e f}=-\frac{1}{R C} u_{p v}+\frac{1}{C} i_{p v}-\frac{1}{C} i_{L}-\dot{u}_{p v r e f}
$$

In this step, the control Lyapunov function is chosen as

$$
V_{1}=\frac{1}{2} e_{1}^{2}
$$

Its derivative can be written as follows:

$$
\dot{V}_{1}=e_{1} \dot{e}_{1}=e_{1}\left(-\frac{1}{R C} u_{p v}+\frac{1}{C} i_{p v}-\frac{1}{C} i_{L}-\dot{u}_{p v_{-} r e f}\right)
$$

The main objective to be reached consists in making the error $\mathrm{e}_{1}$ converge to zero and ensure the stability of $\dot{e}_{1}$ by taking $\dot{V}_{1}<0$. To do so, $i_{L}$ is chosen as a stabilizing function (i.e., $\left.i_{L}=i_{L_{\text {rref }}}\right)$. Thus, we set

$$
\dot{e}_{1}=-k_{1} e_{1} ; \text { avec } k_{1}>0
$$

And relation (18) can be written as follows:

$$
-\frac{1}{R C} u_{p v}+\frac{1}{C} i_{p v}-\frac{1}{C} i_{L_{-} r e f}-\dot{u}_{p v r e f}=-k_{1} e_{1}
$$

From relation (22), the virtual command is deduced such as

$$
i_{L \_r e f}=C\left(k_{1} e_{1}-\frac{1}{R C} u_{p v}+\frac{1}{C} i_{p v}-\dot{u}_{p v \_r e f}\right)
$$

Stage 2 (current loop $i_{L}$ ). In this stage, the subsystem $\mathrm{S}_{2}$ of the current loop $\mathrm{i}_{\mathrm{L}}$ is considered. As it is seen before, the design of this stage consists in forcing the current $i_{L}$ to follow its reference $i_{L_{-} \text {ref }}$. The tracking error $\mathrm{e}_{2}$ is defined by

$$
e_{2}=i_{L}-i_{L \_r e f}
$$

According to (16) and (24), the dynamic equations of the error $e_{2}$ are deduced:

$$
\dot{e}_{2}=\dot{i}_{L}-\dot{i}_{L_{-} r e f}=-\frac{r}{L} i_{L}+\frac{1}{L} u_{p v}-\frac{1}{L} u_{m}-\dot{i}_{L_{-} r e f}
$$

The subsystem of the PVG side consists of two second-order subsystems (S1) and (S2). According to relations (18), (24), and (25), we obtain the error system (e1, e2)

$$
\begin{aligned}
& e_{2}=i_{L}-i_{L_{-} r e f} \Longrightarrow i_{L}=e_{2}+i_{L_{-} r e f} \\
& \dot{e}_{1}=-\frac{1}{R C} u_{p v}+\frac{1}{C} i_{p v}-\frac{1}{C}\left(e_{2}+i_{L_{-} r e f}\right)-\dot{u}_{p v \_r e f} \\
& \dot{e}_{2}=-\frac{r}{L} i_{L}+\frac{1}{L} u_{p v}-\frac{1}{L} u_{m}-\dot{i}_{L_{-} r e f}
\end{aligned}
$$

The quadratic function of Lyapunov is applied in (27)

$$
V_{2}\left(e_{1}, e_{2}\right)=V_{1}+\frac{1}{2} e_{2}^{2}=\frac{1}{2} e_{1}^{2}+\frac{1}{2} e_{2}^{2}
$$

whose derivative is written below after an elementary calculation

$$
\begin{aligned}
& \dot{V}_{2}\left(e_{1}, e_{2}\right) \\
&=e_{1} \underbrace{\left(-\frac{1}{R C} u_{p v}+\frac{1}{C} i_{p v}-\frac{1}{C} i_{L \_r e f}-\dot{u}_{p v \_r e f}\right)}_{-k_{1} e_{1}} \\
&+e_{2} \underbrace{\left(-\frac{r}{L} i_{L}+\frac{1}{L} u_{p v}-\frac{1}{L} u_{m}-\dot{i}_{L \_r e f}-\frac{1}{C} e_{1}\right)}_{-k_{2} e_{2}}
\end{aligned}
$$

$K_{2}$, being a positive constant, is defined to guarantee the negativity of $V_{2}$. Besides, for this stage, it is essential to make the error $\mathrm{e}_{2}$ converge to zero; in these conditions the choice of the real command $m_{h_{-} r e g}$ becomes evident. Using (16) and (28), we obtain

$$
m_{h \_r e g}=\frac{L}{u_{d c}}\left(k_{2} e_{2}-\frac{r}{L} i_{L}+\frac{1}{L} u_{p v}-\dot{i}_{L_{-} r e f}-\frac{1}{C} e_{1}\right)
$$

Thanks to this choice, the derivative of the control Lyapunov function is reduced to

$$
\dot{V}_{2}=-k_{2} e_{2}-k_{1} e_{1}
$$

$\dot{V}_{2}$ can be negative definite $\left(\dot{V}_{2}<0\right)$ or semidefinite $\left.\dot{V}_{2} \leq 0\right)$ which proves the asymptotic stability towards the origin of the subsystem $\left(S_{2}\right)$.

\subsection{Backstepping Based Cascade Control Sizing on the Grid} Side. Referring to the MCS of the grid side in Figure 7, it is noticed that, according to the control chain highlighted in green, the DC link voltage $u_{d c}$ is considered as an output. The controller $C_{4}$, not only ensures the voltage control $u_{d c}$, but also provides the reference current $i_{\text {mo_ref }}$. Afterwards, the latter reference current is used by the block "Control P-Q" in order to determine the reference currents $I_{r_{-} d q}$ of the multivariable controller $C_{3}$, which in turn monitors the 
currents injected into the grid. With this intention, it must provide the main control commands $\left(m g_{d_{-} r e g}\right.$ and $\left.m g_{q_{-} \text {reg }}\right)$ to be applied to the three-phase inverter.

The DC voltage controller is exploited to produce the reference current. Its target consists on keeping the voltage constant on the DC side. The current loop is considered as the inner loop while the DC voltage loop presents the outer loop. The DC link voltage is controlled by means of the converter side DC current as follows:

$$
\left(S_{3}\right) \Longrightarrow \frac{d u_{d c}}{d t}=\dot{u}_{d c}=-\frac{1}{R_{1} C_{1}} u_{d c}+\frac{1}{C_{1}} i_{m h}-\frac{1}{C_{1}} i_{m o}
$$

While the current controllers are used to achieve the tracking of the grid currents $I_{r_{-} d q}$, the control laws are obtained in (32) as follows:

$$
\begin{aligned}
& \left(S_{4}\right) \\
& \Longrightarrow\left\{\begin{array}{l}
\frac{d i_{r d}}{d t}=i_{r d}=\frac{1}{L_{1}}\left(-r_{1} i_{r d}+v_{m d}-v_{r d}+L_{1} \omega i_{r q}\right) \\
\frac{d i_{r q}}{d t}=i_{r q}=\frac{1}{L_{1}}\left(-r_{1} i_{r q}+v_{m q}-v_{r q}-L_{1} \omega i_{r d}\right)
\end{array}\right.
\end{aligned}
$$

(i) $m g_{d_{-} r e g}$ and $m g_{q_{-} r e g}$ are the three-phase inverter command variables.

As the grid side subsystem is a second-order system, its design is performed in two stages.

Stage 1 (DC link voltage loop). The subsystem (S3) described by relation (31) is considered and the DC link voltage is defined as an output while the current $i_{\text {mo }}$ is treated as a virtual command. This step consists in identifying the error $\mathrm{e}_{3}$, as the difference between the DC link voltage $u_{d c}$ and its reference $u_{d c_{\text {_ref }}}$ such as

$$
e_{3}=u_{d c}-u_{d c_{-} r e f}
$$

The same structure is kept and the Backstepping cascade control is done according to the same process established on the PVG side. The relation of the virtual command $i_{\text {mo_ref }}$ is written by

$$
i_{\text {mo_ref }}=C_{1}\left(k_{3} e_{3}-\frac{1}{R_{1} C_{1}} u_{d c}+\frac{1}{C_{1}} i_{m h}-\dot{u}_{d c_{-} r e f}\right)
$$

Stage 2 (grid current loop). According to the MCS in Figures 4 and 8 , the currents $i_{r d}$ and $i_{r q}$ are considered as outputs and the voltages $v_{m d}$ and $v_{m q}$ are treated as virtual commands. As a multivariable controller $C_{4}$ is used, the dq-axis current tracking errors are, respectively, identified as the difference between current $i_{r d}$ and $i_{r q}$ and their references such as

$$
\begin{aligned}
& e_{d}=i_{r d}-i_{r d_{-} r e f} \Longrightarrow i_{r d}=e_{d}+i_{r d \_r e f} \\
& e_{q}=i_{r q}-i_{r q_{-} r e f} \Longrightarrow i_{r q}=e_{q}+i_{r q_{-} r e f}
\end{aligned}
$$

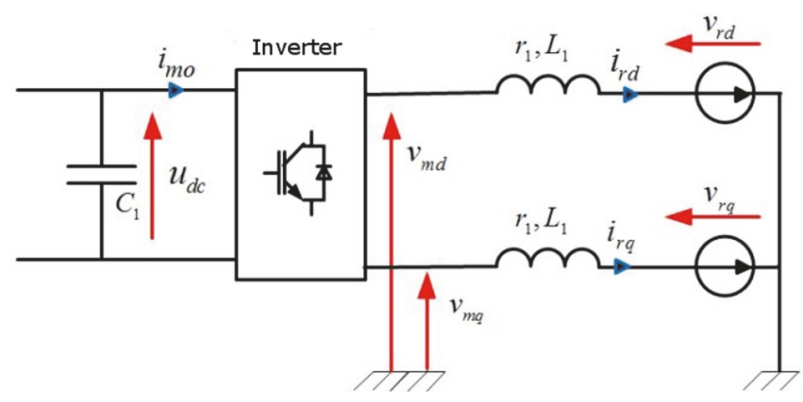

Figure 8: Equivalent scheme of the grid side Photovoltaic installation in the dq frame.

According to (32) and (35), we obtain the dynamic equations of the errors $e_{d}$ and $e_{q}$

$$
\begin{aligned}
& \dot{e}_{d}=\frac{1}{L_{1}}\left(-r_{1} i_{r d}+v_{m d}-v_{r d}+L_{1} \omega i_{r q}\right)-\dot{i}_{r d_{\_} r e f} \\
& \dot{e}_{q}=\frac{1}{L_{1}}\left(-r_{1} i_{r q}+v_{m q}-v_{r q}-L_{1} \omega i_{r d}\right)-\dot{i}_{r q \_r e f}
\end{aligned}
$$

Taking into account relations (10), (35), and (36) and the dynamic equation of the $e_{3}$ error, we obtain, after an elementary calculation, the grid side subsystem relation formed by $\left(S_{3}\right)$ and $\left(S_{4}\right)$ within the errors space $\left(e_{3}, e_{d}, e_{q}\right)$

$$
\begin{aligned}
\dot{e}_{3}= & -\frac{1}{R_{1} C_{1}} u_{d c}+\frac{1}{C_{1}} i_{m h}-\frac{1}{C_{1}} \frac{1}{2}\left(m_{d} i_{r d}+m_{q} i_{r q}\right) \\
& -\dot{u}_{d c \_r e f}
\end{aligned}
$$

Then, $i_{r d}$ and $i_{r q}$ of relation (37) are replaced by their expressions obtained in the relation (35), we obtain the following relation:

$$
\begin{aligned}
& \dot{e}_{3}
\end{aligned}
$$

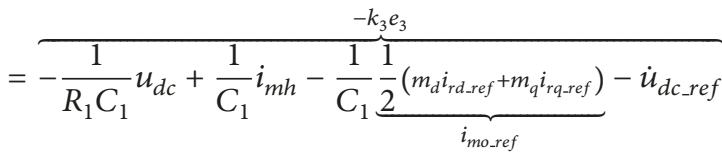

$$
\begin{aligned}
& -\frac{1}{2 C_{1}}\left(m_{d} e_{d}+m_{q} e_{q}\right)
\end{aligned}
$$

the latter equation can be written in a simpler form

$$
\dot{e}_{3}=-k_{3} e_{3}-\frac{1}{2 C_{1}}\left(m_{d} e_{d}+m_{q} e_{q}\right)
$$

The design of this step consists in forcing the current $i_{r d}$ and $i_{r q}$ injected to the grid to follow their references, namely, to force the errors $e_{d}$ and $e_{q}$ to converge towards zero. In this case, the quadratic function of Lyapunov $V_{3}$ is increased by two terms

$$
V_{4}=V_{3}+V_{d}+V_{q}=\frac{1}{2} e_{3}^{2}+\frac{1}{2} e_{d}^{2}+\frac{1}{2} e_{q}^{2}
$$


when (40) is derived, we obtain

$$
\dot{V}_{4}=e_{3} \dot{e}_{3}+e_{d} \dot{e}_{d}+e_{q} \dot{e}_{q}
$$

By introducing the dynamic equation of the error $e_{3}$ and the expression (36) in the relation (41) and after a little long but elementary calculation, (41) becomes as shown below

$$
\begin{aligned}
\dot{V}_{4}= & -k_{3} e_{3}^{2}+e_{d}(\underbrace{\frac{1}{L_{1}}\left(-r i_{r d}+v_{m d}-v_{r d}+L_{1} \omega i_{r q}\right)-\frac{e_{3}}{2 C_{1} u_{d c}} v_{m d_{\_r e f}}-\dot{i}_{r d \_r e f}}_{-k_{d} e_{d}}) \\
& +e_{q}(\underbrace{\frac{1}{L_{1}}\left(-r i_{r q}+v_{m q}-v_{r q}-L_{1} \omega i_{r d}\right)-\frac{e_{3}}{2 C_{1} u_{d c}} v_{m q \_r e f}-i_{r q \_r e f}}_{-k_{q} e_{q}})
\end{aligned}
$$

A wise choice of the tensions $v_{m d}$ and $v_{m q}$ would make $\dot{V}_{d}$ and $\dot{V}_{q}$, respectively, negative and would ensure the stability at the origin of the subsystem on the grid side. In this context, $v_{m d}$ and $v_{m q}$ are considered as virtual commands with their references $v_{m d_{\text {rref }}}$ and $v_{\text {mq_ef }}$, respectively:

$$
\begin{aligned}
& v_{\text {md_ref }}=\frac{2 C_{1}}{2 C_{1} u_{d c}-e_{3}}\left(-k_{d} e_{d}\right. \\
& \left.+\frac{1}{L_{1}}\left(r i_{r d}+v_{r d}-L_{1} \omega i_{r q}\right)+i_{r d \_r e f}\right) \\
& v_{\text {mq_ref }}=\frac{2 C_{1}}{2 C_{1} u_{d c}-e_{3}}\left(-k_{q} e_{q}\right. \\
& \left.+\frac{1}{L_{1}}\left(r i_{r q}+v_{r q}+L_{1} \omega i_{r d}\right)+i_{r q \_r e f}\right)
\end{aligned}
$$

The main target of this stage is to control the grid currents. which are needed to determine the control commands $m_{\text {d_reg }}$ and $m_{q_{\text {rreg }}}$ to be applied at the entrance of the three-phase inverter.

$$
\begin{aligned}
& m_{d_{-} r e g}=\frac{v_{m d_{\_} r e f}}{u_{d c}} \\
& m_{q_{-} \text {reg }}=\frac{v_{m q-r e f}}{u_{d c}}
\end{aligned}
$$

\section{Results of Simulation}

The instantaneous average model of the overall system is developed under the software package Matlab/Simulink environment. The results of simulation are carried out using the following conditions:

$$
\begin{aligned}
& P=1 k W, \\
& C=220 \mu F, \\
& R=100 k \Omega,
\end{aligned}
$$

$$
\begin{aligned}
L & =23 \mathrm{mH}, \\
C_{1} & =5000 \mu \mathrm{F}, \\
R_{1} & =10 \mathrm{k} \Omega, \\
r_{1} & =0.0002 \Omega, \\
L_{1} & =1 \mathrm{mH}, \\
U_{r} & =380 \mathrm{~V}, \\
f & =50 \mathrm{~Hz}
\end{aligned}
$$

and with the following control parameter values which are acquired using trial and error for the purpose of satisfying the already mentioned theoretical conditions during the previous section:

$$
\begin{aligned}
k_{u p v} & =76, \\
k_{i L} & =10^{4}, \\
k_{u d c} & =2000, \\
k_{d} & =k_{q}=10^{5}
\end{aligned}
$$

The performances of the designed nonlinear controller will be evaluated by simulation on a three-phase low-voltage grid-connected PV system under different operating scenarios.

Case 1 (control under sudden irradiation variations). The irradiation can quickly change by environmental conditions. Four irradiation steps were simulated and irradiance goes from $1000 \mathrm{~W} / \mathrm{m}^{2}$ to $800 \mathrm{~W} / \mathrm{m}^{2}$, then it steps down to $600 \mathrm{~W} / \mathrm{m}^{2}$ and finally steps up to $900 \mathrm{~W} / \mathrm{m}^{2}$. Under constant temperature, when a step change of irradiance happens, the ability of MPP tracking is demonstrated for the P\&O method. As a result, the power delivered into the grid will be optimized since the maximum PV current and voltage are extracted. Figures 9 and 10 show the results obtained with the $\mathrm{P} \& \mathrm{O}$ method. They show the $\mathrm{P} \& \mathrm{O}$ good tracking in case of fastchanging conditions. 


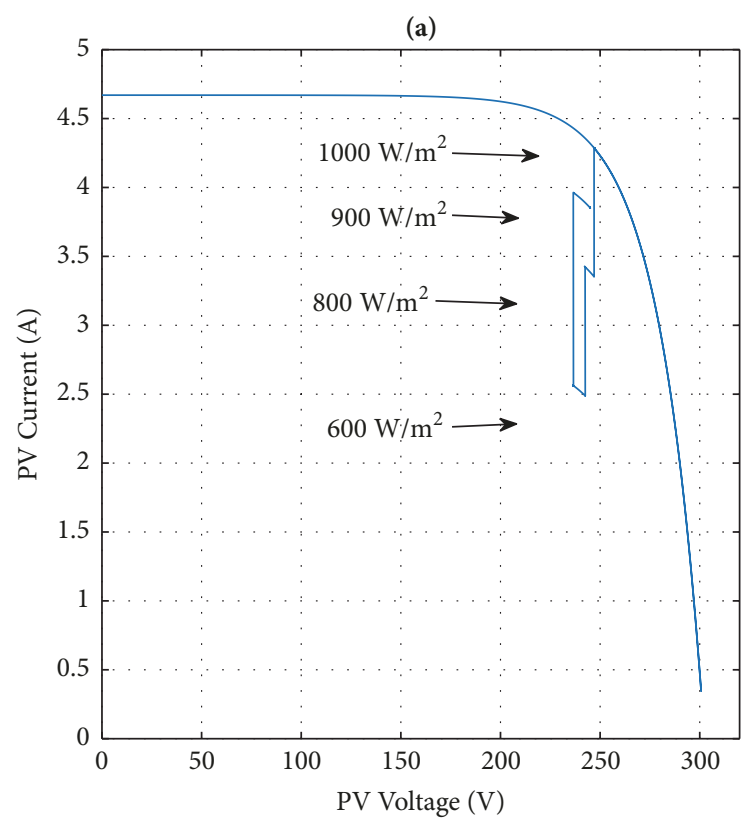

Figure 9: I-V curve with P\&O.

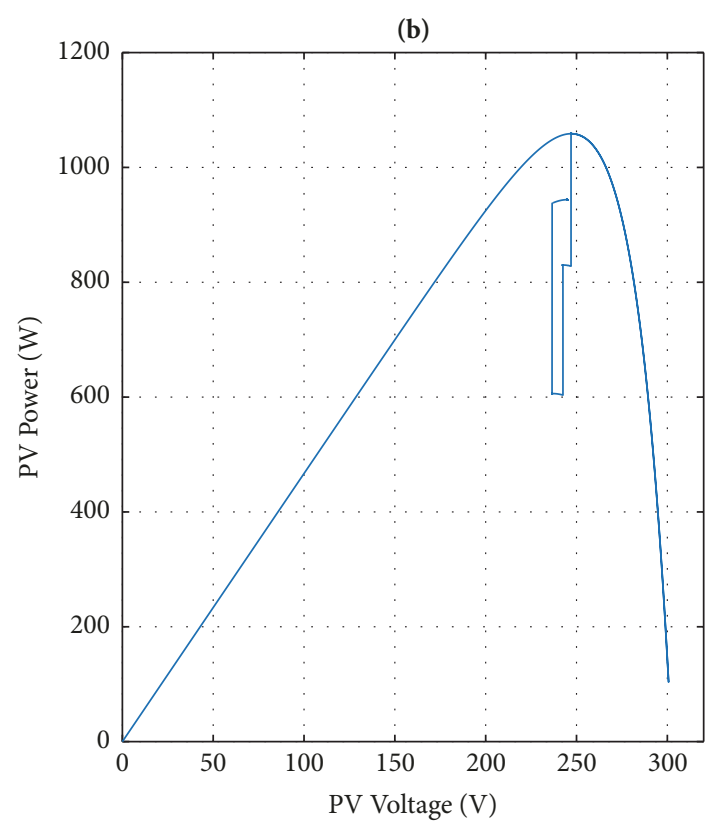

Figure 10: P-V curve with P\&O.

Furthermore, the perfect follow-up of the PV voltage and its reference is depicted in Figure 11.

The reference DC link voltage is fixed at $700 \mathrm{~V}$. The DC/DC boost converter is used to maintain the DC link voltage at the desired value through the DC link capacitor. In fact, it is noticed from Figure 12 that the changing solar irradiation has no significant effect on the DC link voltage and it remains at $700 \mathrm{~V}$.

In Figures 13 and 14, the current loop controller is validated since the measured grid currents are tracking perfectly their references and vary significantly whenever a

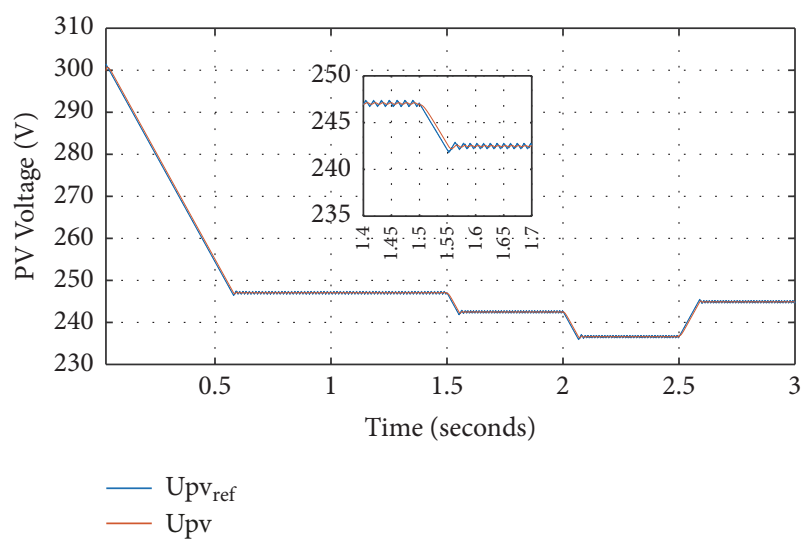

FIGURE 11: $U_{\mathrm{pv}}$ voltage reference and measured.

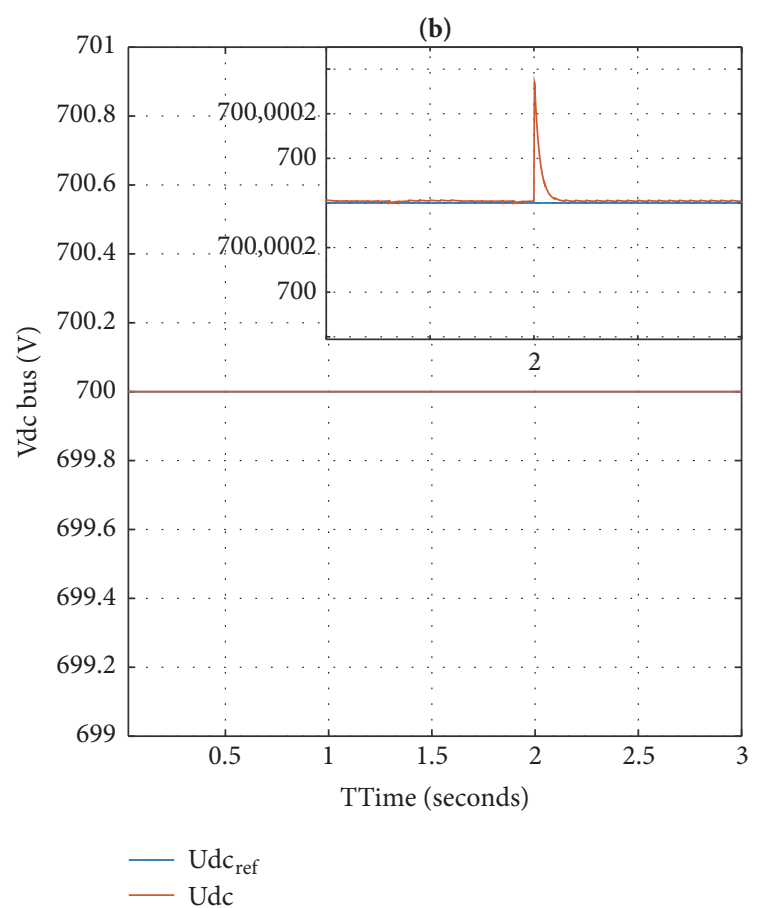

FIGURE 12: DC link voltage.

variation of solar irradiation happens. A detailed view on the controller performance during irradiation change (at $t=2 \mathrm{sec}$ ) is provided by the zoom of Figure 14. From the two figures, it can be recognized that the current controller response is very fast and is reaching its reference in a brief span.

Case 2 (control under voltage dips without/with current amplitude limitation). Voltage dips are considered as one of the most challenging problems in grid-connected PV systems. The proposed control strategy have to ensure a good voltage dip immunity. In fact, due to a voltage dip at $\mathrm{t}=0.08 \mathrm{sec}$, grid voltages have decreased by $50 \%$ and maintain this level for $0.06 \mathrm{sec}$. Figure 15 highlights the impact of the grid voltage dip on the currents injected into the grid without amplitude limitation. The grid currents have 


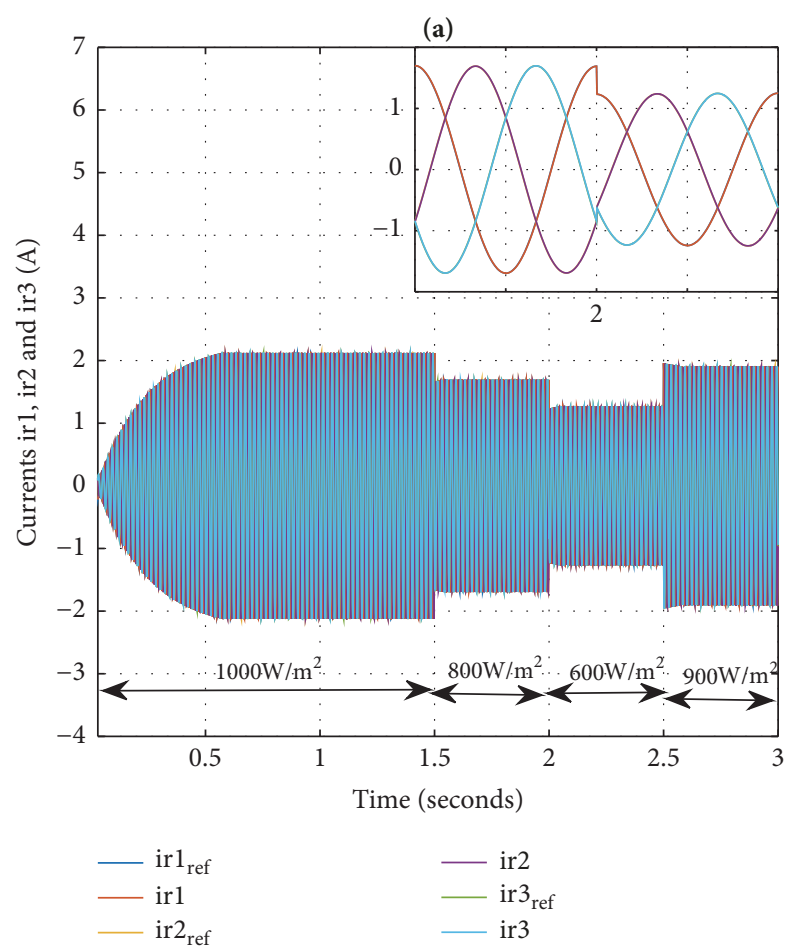

FIGURE 13: Grid currents under irradiation variation.

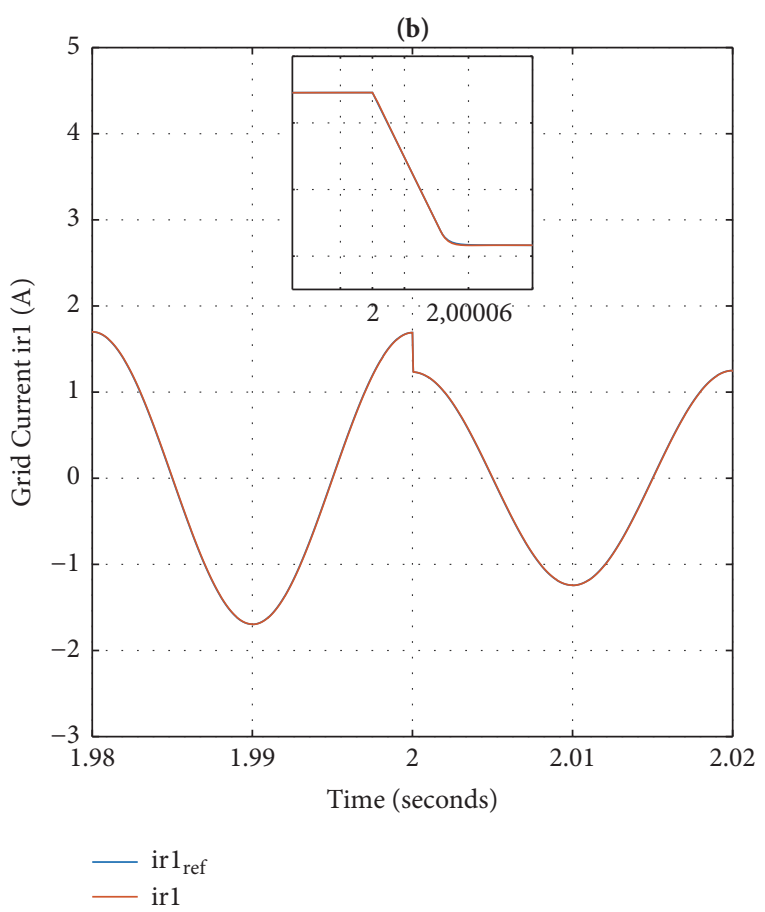

FIGURE 14: Grid current irl measured and its reference.

increased by $50 \%$ accordingly in order to mitigate the power loss caused by voltage dips. Furthermore, one of the aims of the Backstepping control strategy is to keep the DC link voltage stable independently of the power variation. Figure 16 is validating the DC link voltage controller that provides a good tracking of the measured dc link voltage to its reference.

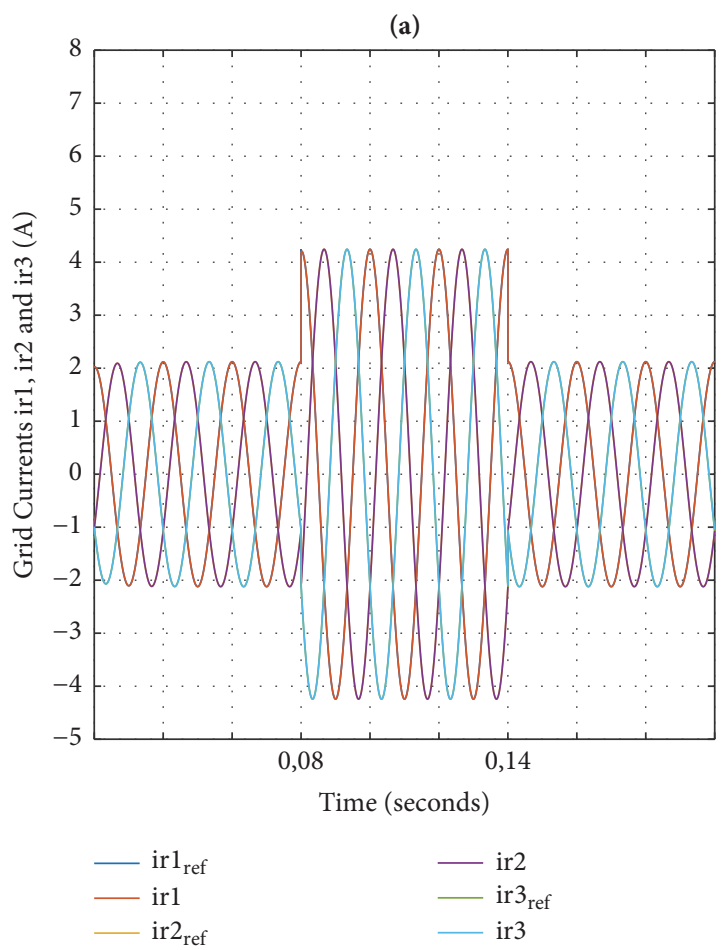

FIGURE 15: The voltage dip effect: on grid currents without limitation of their amplitudes.

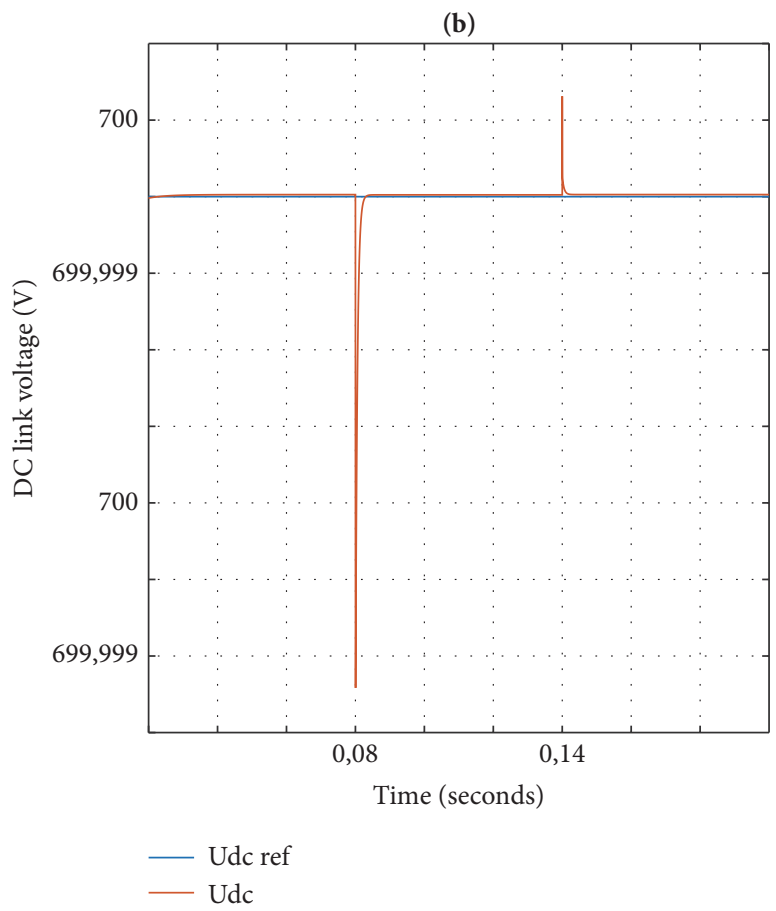

FIgURE 16: The voltage dip effect: on DC link voltage.

At $\mathrm{t}=0.08 \mathrm{sec}$ and $\mathrm{t}=0.14 \mathrm{sec}$, $\mathrm{a}$ transient phenomenon can be discerned due to voltage dip. The DC controller is trying to keep the DC link at the same constant value and reduce very fast the error. 


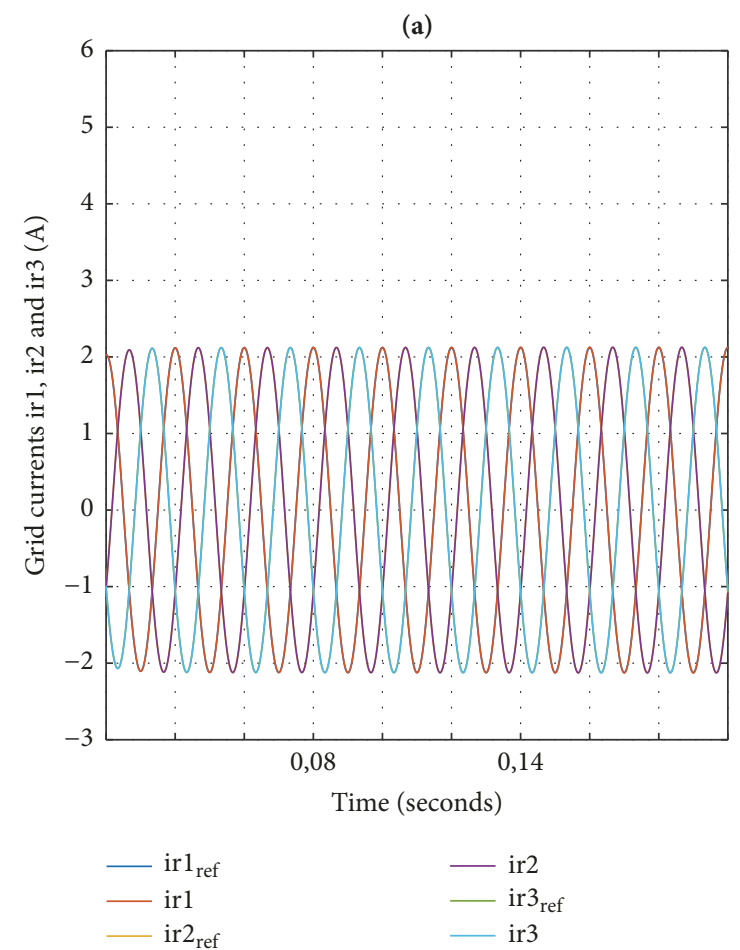

FIGURE 17: The voltage dip effect: on grid currents with limitation of their amplitudes.

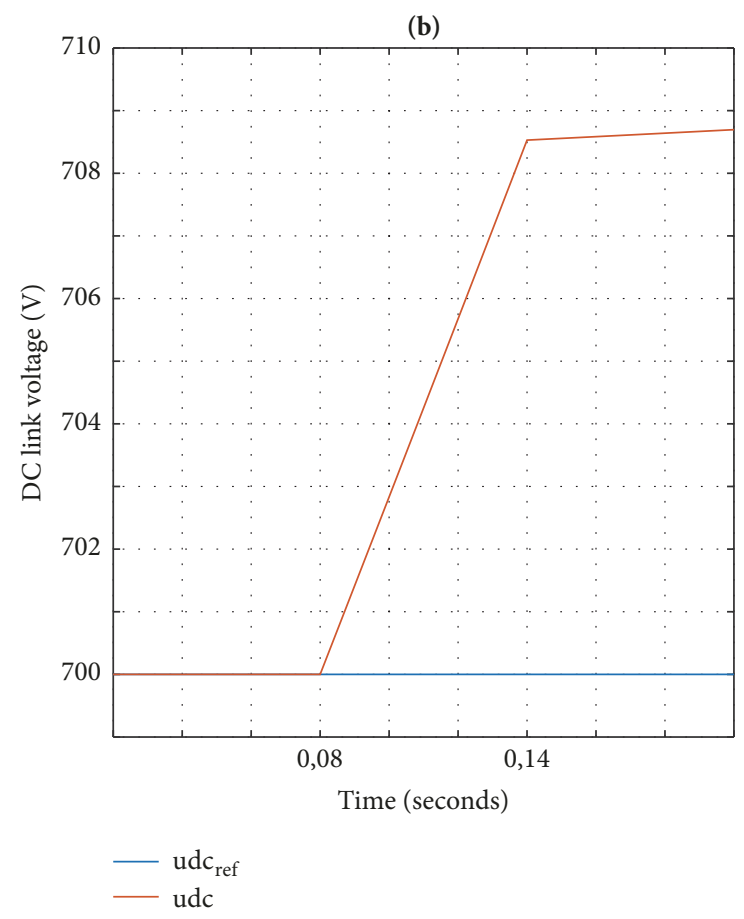

FIGURE 18: The voltage dip effect: on DC link voltage.

Voltage dip has no significant impact on grid currents with amplitude limitation as depicted in Figure 17. The grid currents remain unchanged while the DC link voltage in Figure 18 has gradually increased during the voltage dip to reach a steady-state with a new value $(708.7 \mathrm{~V})$.

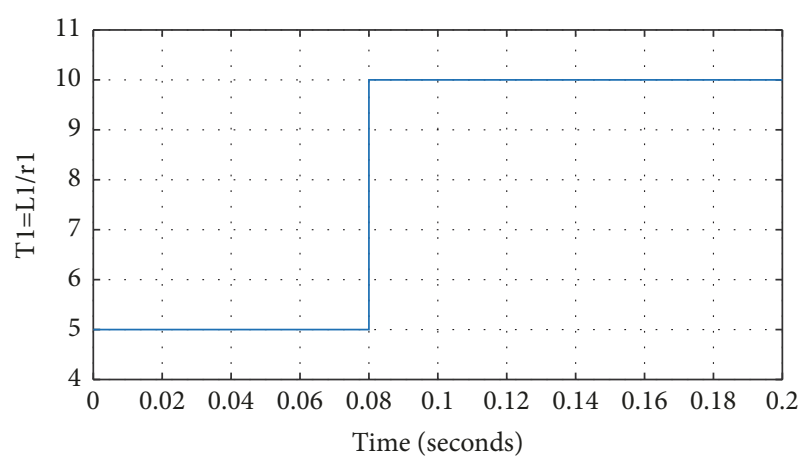

Figure 19: Time constant of the grid line.

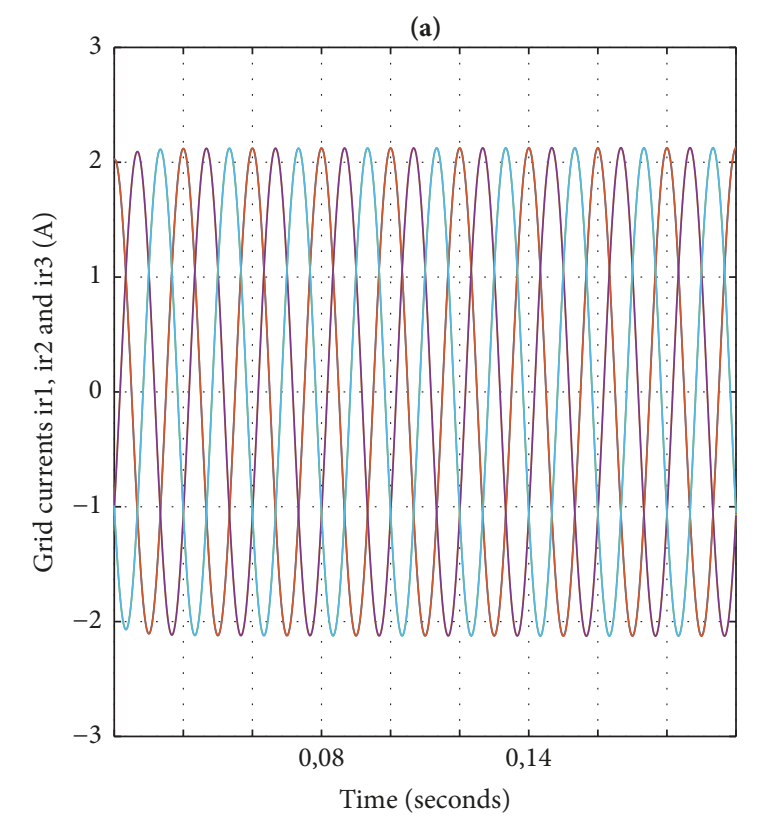

FIgURE 20: The effect of 50\% line resistance sudden decrease on the grid currents.

Case 3 (control sensitivity to parameter variations). The parameters of the PV system can suddenly vary. As a result, it is necessary to evaluate the robustness and reliability of the Backstepping control strategy.

Specifically, a reduction of $50 \%$ in resistance rl leads to an increase of $100 \%$ of the time constant $(\mathrm{T} 1=\mathrm{L} 1 / \mathrm{r} 1)$ as shown in Figure 19. The parameter change is performed at $\mathrm{t}=0.08 \mathrm{sec}$.

The results of simulation given in Figure 20 prove the reliability of the Backstepping control to sudden parametric variations. In fact, it shows capability to deliver the desired output power to the grid with unity power factor; in other words, it keeps the output current in phase with the grid voltage. Grid currents remain unchanged when the resistance value varies. The simulation results obtained confirm the excellent performance and the robustness of the control by Backstepping.

Case 4 (control under measurement uncertainties). Under constant temperature $\left(\mathrm{T}=25^{\circ} \mathrm{C}\right)$, the PV system is subjected 


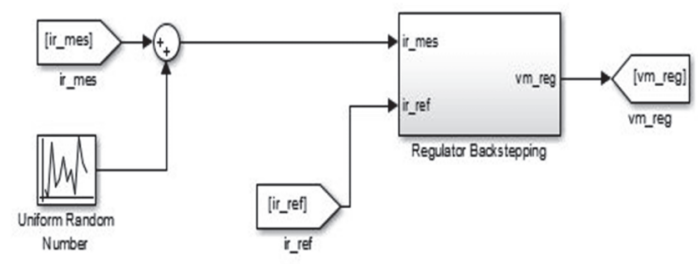

FIGURE 21: Measurement uncertainties: random error insertion in the current control loop.

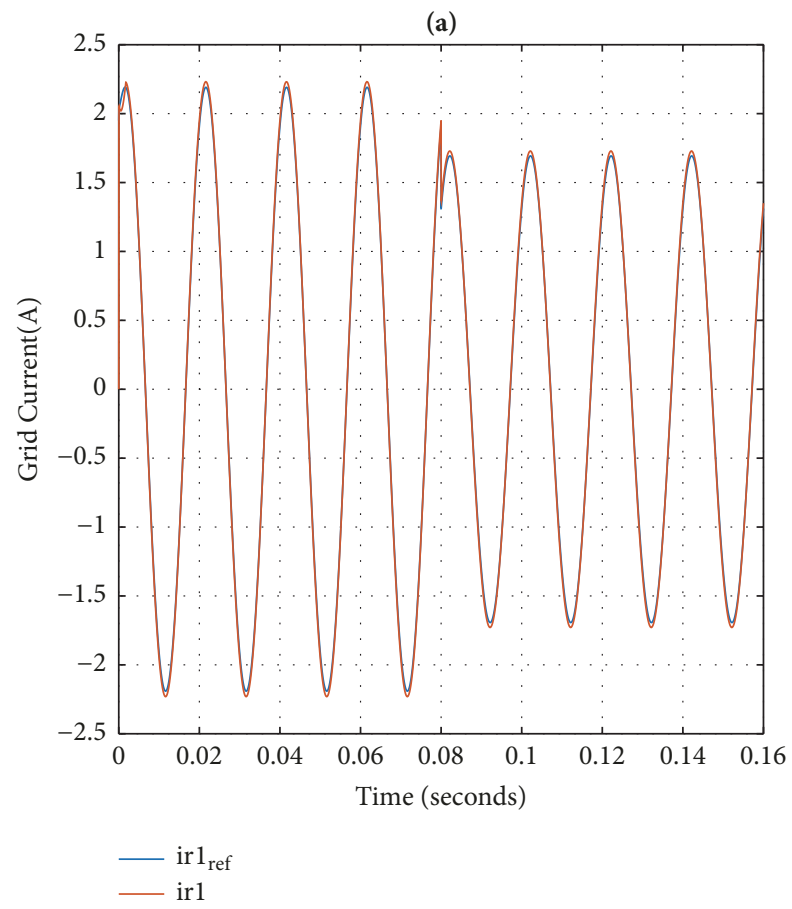

FIGURE 22: Measurement uncertainty effect on grid currents: noise with an amplitude of $+/-10$ of grid current amplitude.

to measurement uncertainty by inserting a noise, called also a random error, as an external disturbance at the entrance of the Backstepping control bloc of the current control loop as portrayed in Figure 21. First, the noise is of amplitude of $+/$ $10 \%$ and then $+/-20 \%$ of the grid current amplitude.

Besides, the solar irradiation level steps down from $1000 \mathrm{~W} / \mathrm{m}^{2}$ to $800 \mathrm{~W} / \mathrm{m}^{2}$ curves at $\mathrm{t}=0.08 \mathrm{sec}$. Figures 22 and 23 show the robustness of the Backstepping control to measurement uncertainties. It is worth noting that, at the presence of noise, grid currents vary slightly and the unity power factor is always maintained.

\section{Conclusion}

A robust nonlinear Backstepping Controller is proposed in this paper for a grid-connected PV system. The EMR and the MCS are proposed in order to provide, respectively, the instantaneous average model and a cascade control structure. For superior tracking efficiency, a P\&O based MPPT algorithm is employed to extract maximum power from PV

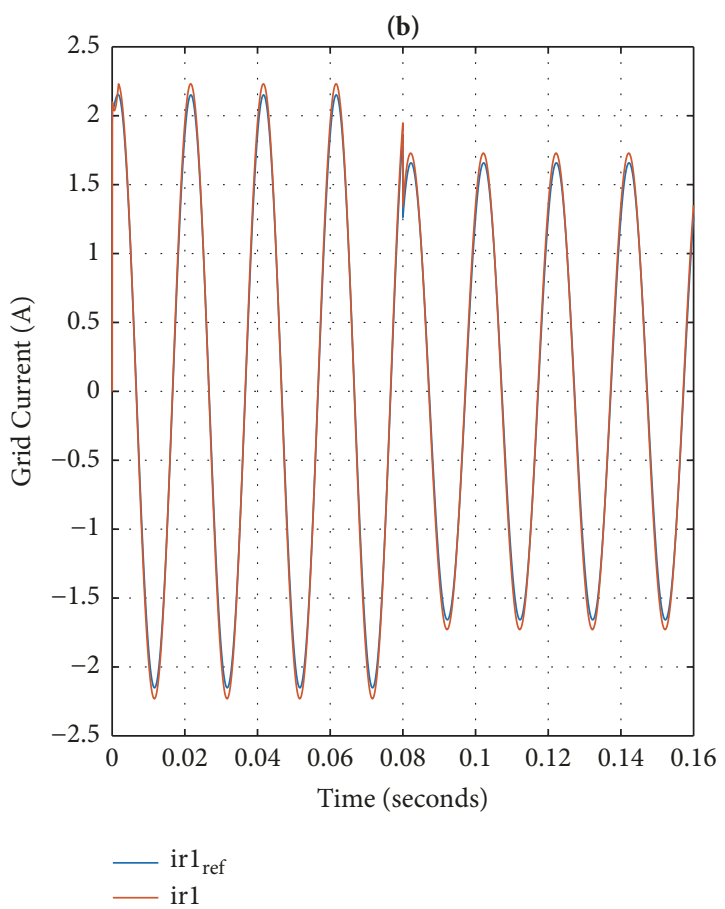

FIGURE 23: Measurement uncertainty effect on grid currents: noise with an amplitude of $+/-20$ of grid current amplitude.

panels. The control strategy is designed in order to control all cascade loops in the conversion chain. The system responses are performed when fast-changing solar irradiation, voltage dip, parametric variations, and measurement uncertainties are experienced. The Backstepping control addresses all the already quoted challenges and the problem of controlling a three-phase grid-connected PV system is addressed. Simulations have been conducted using Matlab/Simulink validating the functionality, robustness, and simplicity of the algorithm.

\section{Data Availability}

The data used to support the findings of this study are available from the corresponding author upon request.

\section{Conflicts of Interest}

The authors declare that they have no conflicts of interest.

\section{References}

[1] M. A. Green, "Photovoltaic principles," Physica E: Low-dimensional Systems and Nanostructures, vol. 14, no. 1-2, pp. 11-17, 2002.

[2] G. Xu, P. Moulema, L. Ge, H. Song, and W. Yu, A Unified Framework for Secured Energy Resource Management in Smart Grid Smart Grid, CRC Press, 2016.

[3] W. Xiao and W. G. Dunford, "A modified adaptive hill climbing MPPT method for photovoltaic power systems," in Proceedings of the 35th Annual Power Electronics Specialists Conference (PESC '04), vol. 3, pp. 1957-1963, IEEE, June 2004. 
[4] D. Hohm and M. Ropp, "Comparative study of maximum power point tracking algorithms using an experimental, programmable, maximum power point tracking test bed," in Proceedings of the 28th IEEE Photovoltaic Specialists Conference, pp. 1699-1702, IEEE, Anchorage, AK, USA, 2000.

[5] A. Badis, M. H. Boujmil, and M. N. Mansouri, "A comparative study on maximum power point tracking techniques of photovoltaic systems," International Journal of Energy Optimization and Engineering, vol. 7, no. 1, pp. 66-85, 2018.

[6] A. Badis, M. N. Mansouri, and A. Sakly, "PSO and GAbased maximum power point tracking for partially shaded photovoltaic systems," in Proceedings of the 7th International Renewable Energy Congress, IREC 2016, March 2016.

[7] M. H. Boujmil, M. N. Mansouri, and M. F. Mimouni, "Comparative study of the cascade state ad-justment applied to a three phase low volt-age grid connected to a pv systems," STA2009, 2009.

[8] G. A. Raducu, Control of Grid Side Inverter in a B2B Configuration for WT Applications, [Master, thesis], Aalborg University, 2008.

[9] M. Amirabadi, "Analog control of AC link universal power converters: The key to very high frequency AC link conversion systems," in Proceedings of the 30th Annual IEEE Applied Power Electronics Conference and Exposition, APEC 2015, pp. 23012308, March 2015.

[10] M. Basavaraj and P. Nagabhushan, "Solar based high frequency AC link inverter," International Research Journal of Engineering and Technology (IRJET), vol. 3, no. 5, pp. 828-834, 2016.

[11] B. N. Alajmi, K. H. Ahmed, S. J. Finney, and B. W. Williams, "Fuzzy-logic-control approach of a modified hill-climbing method for maximum power point in microgrid standalone photovoltaic system," IEEE Transactions on Power Electronics, vol. 26, no. 4, pp. 1022-1030, 2011.

[12] T. L. Kottas, Y. S. Boutalis, and A. D. Karlis, "New maximum power point tracker for PV arrays using fuzzy controller in close cooperation with fuzzy cognitive networks," IEEE Transactions on Energy Conversion, vol. 21, no. 3, pp. 793-803, 2006.

[13] J. Li and H. Wang, "Maximum power point tracking of photovoltaic generation based on the fuzzy control method," in Proceedings of the 1st International Conference on Sustainable Power Generation and Supply (SUPERGEN '09), pp. 1-6, Nanjing, China, April 2009.

[14] D. Menniti, A. Pinnarelli, and G. Brusco, "Implementation of a novel fuzzy-logic based MPPT for grid-connected photovoltaic generation system," in Proceedings of the 2011 IEEE PES Trondheim PowerTech: The Power of Technology for a Sustainable Society, POWERTECH 2011, June 2011.

[15] B. Yang, W. Li, Y. Zhao, and X. He, "Design and analysis of a grid-connected photovoltaic power system," IEEE Transactions on Power Electronics, vol. 25, no. 4, pp. 992-1000, 2010.

[16] M. H. Boujmil, M. N. Mansouri, and M. F. Mimouni, "Optimal control of PVG interconnected to a three-phase lv network," JTEA2010, 2010.

[17] K. S. Agbli, D. Hissel, M.-C. Péra, and I. Doumbia, "Energetic Macroscopic Representation (EMR): new approach for multiphysics energetic flows modelling," in Proceedings of the 8th Power Plant and Power System Control Symposium, PPPSC 2012, pp. 723-728, September 2012.

[18] D. Chrenko, M. Pera, and D. Hissel, "Fuel cell system modeling and control with energetic macroscopic representation," in Proceedings of the 2007 IEEE International Symposium on Industrial Electronics, pp. 169-174, Vigo, Spain, June 2007.
[19] L. Horrein, A. Bouscayrol, Y. Cheng, and M. E. Fassi, "Multiphysical modeling and description of a permanent magnet synchronous machine using energetic macroscopic representation for EV/HEV applications," in Proceedings of the 2013 15th European Conference on Power Electronics and Applications, EPE 2013, September 2013.

[20] W. Lhomme, P. Delarue, F. Giraud, B. Lemaire-Semail, and A. Bouscayrol, "Simulation of a photovoltaic conversion system using energetic macroscopic representation," in Proceedings of the 15th International Power Electronics and Motion Control Conference and Exposition, EPE-PEMC 2012 ECCE Europe, p. DS3e.76, September 2012.

[21] J. S. Martínez, D. Hissel, M.-C. Péra, and M. Amiet, "Practical control structure and energy management of a testbed hybrid electric vehicle," IEEE Transactions on Vehicular Technology, vol. 60, no. 9, pp. 4139-4152, 2011.

[22] I. Tyukhov, H. Rezk, and P. Vasant, "Modern optimization algorithms and applications in solar photovoltaic engineering," Sustaining Power Resources through Energy Optimization and Engineering, pp. 390-445, 2016.

[23] L. Gyugi and B. R. Pelly, Static Power Frequency Changers: Theory, Design and Applications, Wiley-Interscience, New York, NY, USA, 1976.

[24] J. Oyama, T. Hihuchi, E. Yamada, T. Koga, and T. Lipo, "New control strategies for matrix converter," in Proceedings of the 20th Annual IEEE Power Electronics Specialists Conference, PESC '89 Record, vol. 1, pp. 360-367, 1989.

[25] T. Sobczyk, "Numerical study of control strategies for frequency conversion with a matrix converter," in Proceedings of the Power Electronics and Motion Control, pp. 497-502, Warsaw, Poland, 1994.

[26] J. G. Cho and G. H. Cho, "Soft-switched matrix converter for high frequency direct AC-to-AC power conversion," International Journal of Electronics, vol. 72, no. 4, pp. 669-680, 1992.

[27] J.-P. Hautier and J.-P. Caron, Convertisseurs Statiques, Méthodologie Causale de Modélisation et de Commande, Editions Technip, 1999.

[28] M. R. Barakat, B. Tala-Ighil, H. Chaoui, H. gualous, Y. Slamani, and D. Hissel, "Energetic macroscopic representation of marine current turbine system with loss minimization control," IEEE Transactions on Sustainable Energy, 2017. 


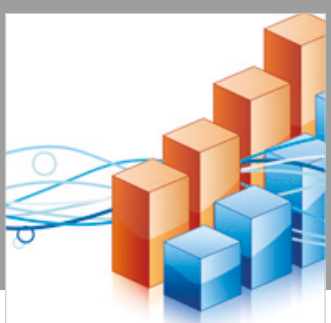

Advances in

Operations Research

\section{-n-m}
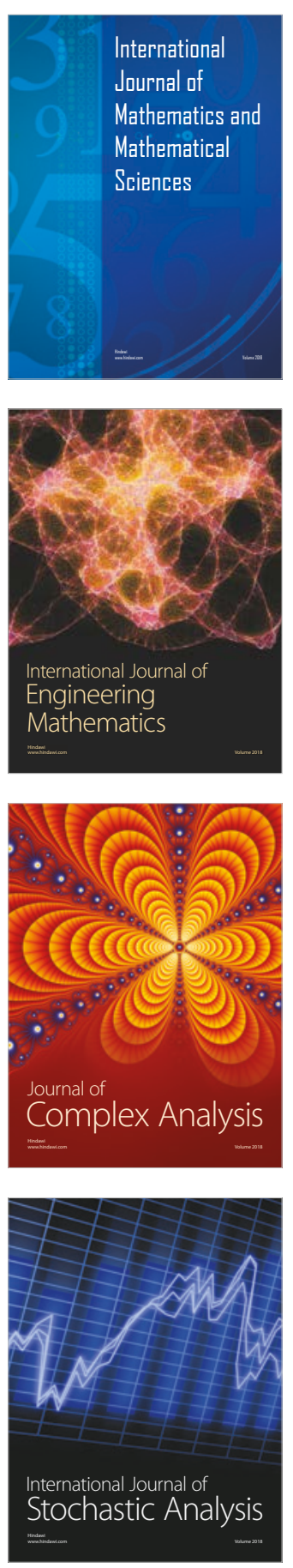
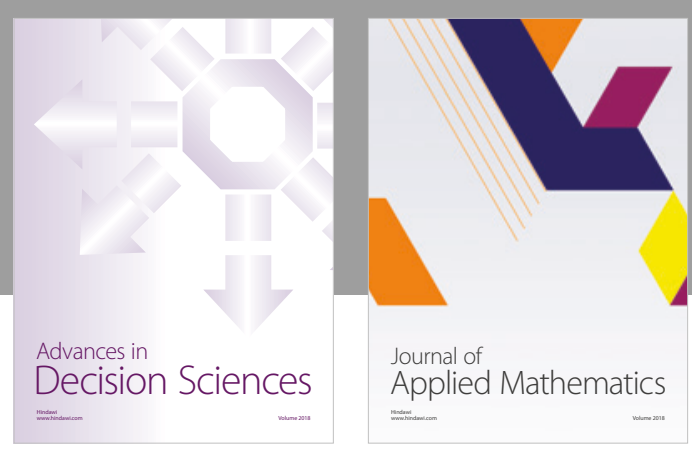

Journal of

Applied Mathematics
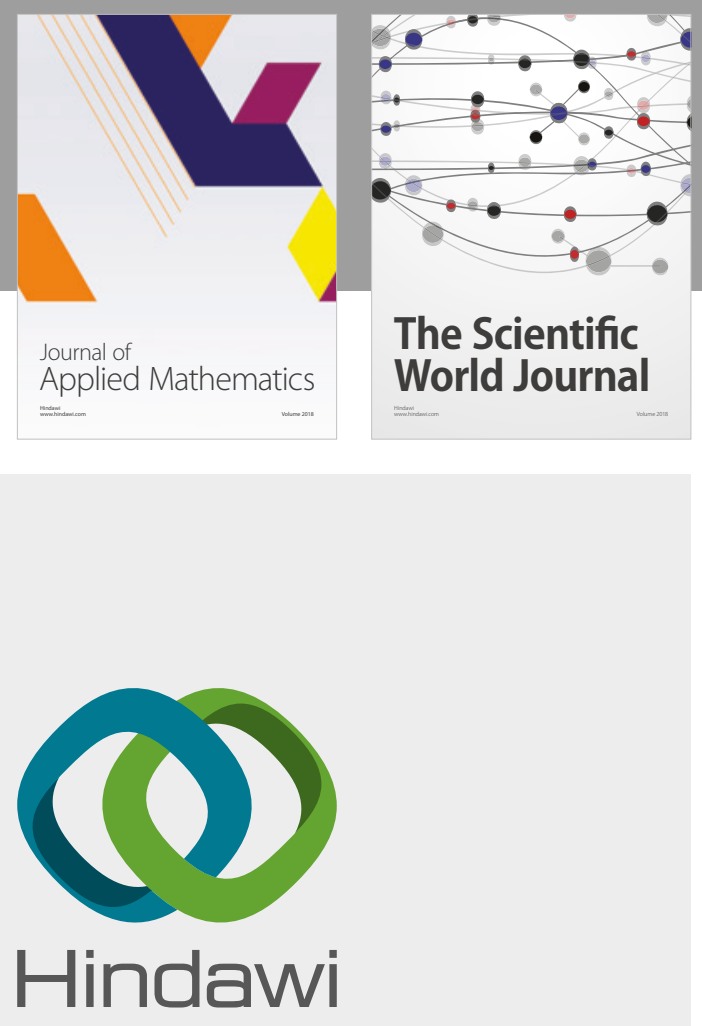

Submit your manuscripts at

www.hindawi.com

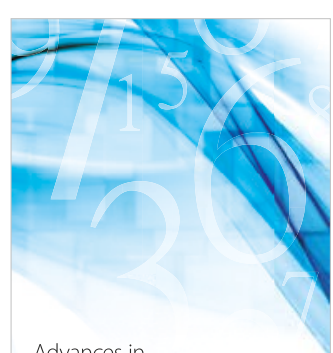

Advances in
Numerical Analysis
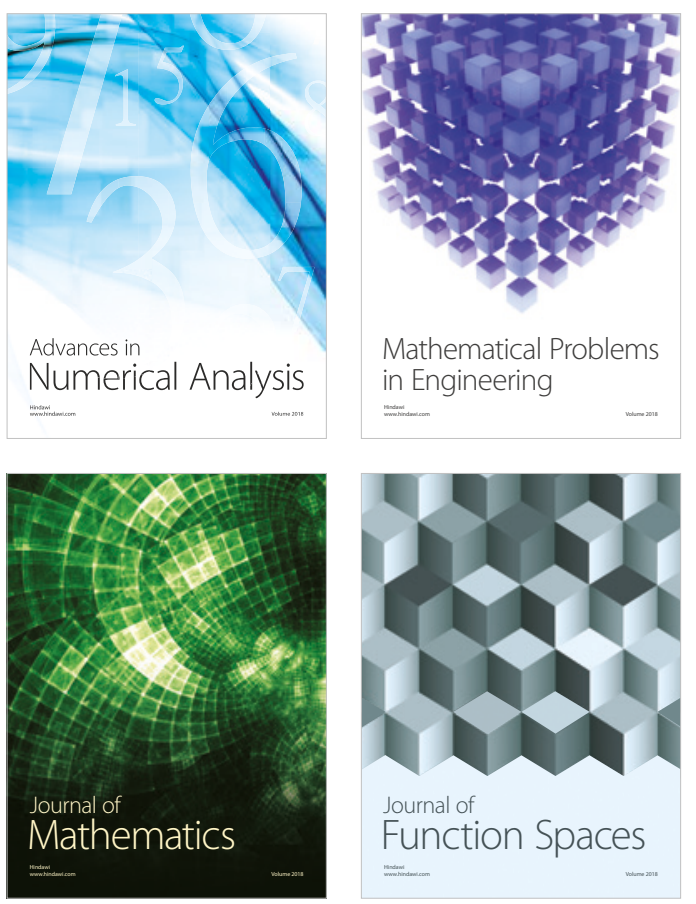

Mathematical Problems in Engineering

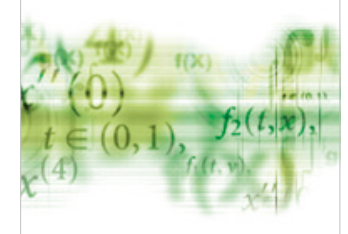

International Journal of

Differential Equations

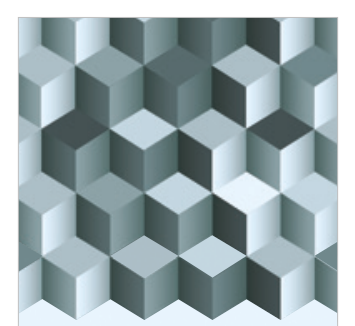

Journal of

Function Spaces

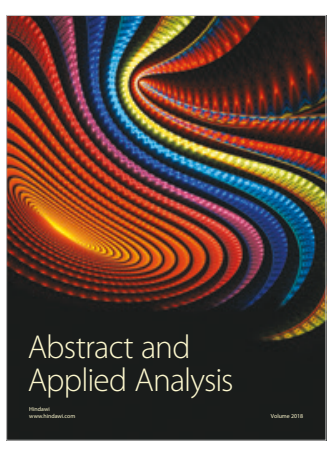

The Scientific

World Journal

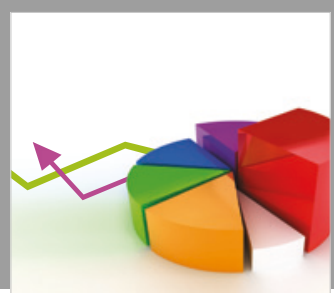

Journal of

Probability and Statistics
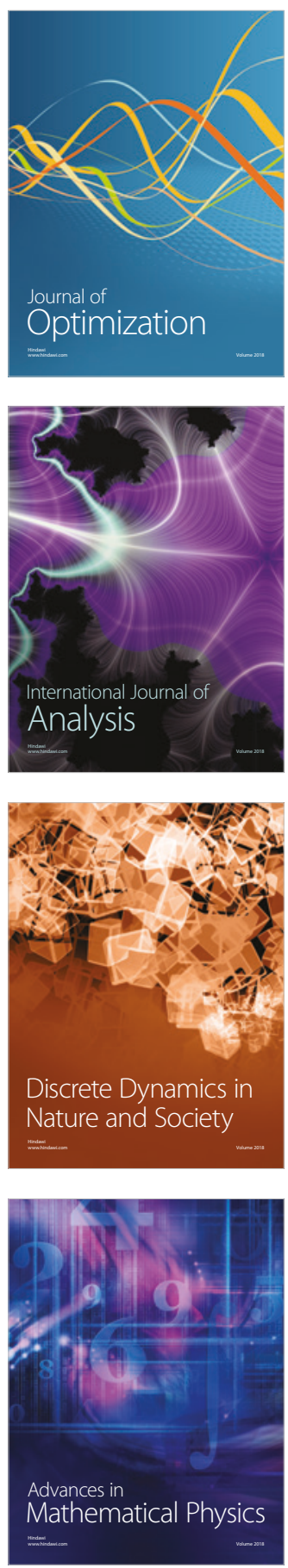